\title{
Post hoc analysis of initial treatments and control status in the INITIAL study: an observational study of newly diagnosed patients with asthma
}

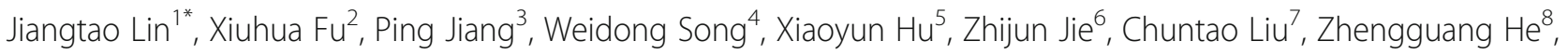
Xiangdong Zhou ${ }^{9}$ and Huaping Tang ${ }^{10}$

\begin{abstract}
Background: The 12-week, multicentre, observational INITIAL study (NCT02143739) assessed asthma severity in newly diagnosed Chinese patients.

Methods: Post hoc analysis of medication combinations prescribed per routine clinical practice at baseline, and the impact on control levels evaluated using 2012 vs 2018 Global Initiative for Asthma (GINA) criteria.

Results: In total, 4491 patients were included in the analysis. At baseline, intermittent, mild, moderate and severe asthma was reported in 3.9, 12.0, 22.6 and $61.6 \%$ of patients, respectively. Most patients (90.2\%) were prescribed inhaled corticosteroid/long-acting $\beta_{2}$ agonist (ICS/LABA). ICS/LABA plus $\geq 1$ additional medication(s) was prescribed to $66.7 \%$ of patients, with leukotriene receptor antagonist (LTRA, 54.7\%) being the most common additional medication. Distribution of ICS/LABA vs ICS/LABA+LTRA was comparable in patients with intermittent (3.2\% vs $3.0 \%)$, mild (11.5\% vs 9.7\%), moderate (21.2\% vs $19.9 \%$ ) and severe asthma (64.1\% vs $67.4 \%)$. Control levels among patients using ICS/LABA+LTRA vs ICS/LABA were comparable using GINA 2012 and lower using GINA 2018 criteria. The proportion of patients using ICS/LABA+LTRA vs ICS/LABA with intermittent, mild, moderate and severe asthma controlled at Week 12 (using GINA 2012) were $78.1 \%$ vs $80.0,86.5 \%$ vs $85.8,78.5 \%$ vs 71.3 , and $59.6 \%$ vs $61.8 \%$, respectively. Using GINA 2018 criteria proportions were $86.8 \%$ vs $95.9,86.1 \%$ vs $93.2,82.1 \%$ vs 85.3 , and $71.9 \%$ vs $77.6 \%$, respectively.
\end{abstract}

Conclusions: Asthma control was not improved by adding LTRA to ICS/LABA and may have been unnecessary for some newly diagnosed patients. These findings were irrespective of the GINA criteria (2012 vs 2018) used and baseline severity.

Keywords: Global initiative for asthma, Inhaled corticosteroid, Leukotriene receptor antagonist, Long-acting $\beta_{2}$ agonist, Symptom control

\footnotetext{
* Correspondence: jiangtao_|@263.net

${ }^{1}$ Department of Pulmonary and Critical Care Medicine, China-Japan

Friendship Hospital, No.2 Yinghua East Street, Chaoyang District, Beijing

100029, China

Full list of author information is available at the end of the article
}

(c) The Author(s). 2020 Open Access This article is distributed under the terms of the Creative Commons Attribution 4.0 International License (http://creativecommons.org/licenses/by/4.0/), which permits unrestricted use, distribution, and reproduction in any medium, provided you give appropriate credit to the original author(s) and the source, provide a link to the Creative Commons license, and indicate if changes were made. The Creative Commons Public Domain Dedication waiver (http://creativecommons.org/publicdomain/zero/1.0/) applies to the data made available in this article, unless otherwise stated. 


\section{Background}

Two pivotal long-term goals of asthma management are symptom control and risk reduction [1]. Evaluation of symptom control constitutes the basis of treatment decisions in a continuous asthma management cycle composed of assessment, treatment adjustment, and response review recommended by the Global Initiative for Asthma (GINA) [1, 2]. Criteria used to assess current clinical control have evolved from a combination of symptoms and lung function (peak expiratory flow [PEF] or forced expiratory volume in $1 \mathrm{~s}\left[\mathrm{FEV}_{1}\right]$ ) endorsed by GINA 2012 [1] to symptoms alone in GINA 2014 [3] and subsequent GINA updates [2]. The removal of lung function from assessment of asthma control is based on the rationale that although still important in predicting risk of exacerbations $[4,5]$, lung function testing results, i.e. spirometry, sometimes provide equivocal or even little utility for determining the level of clinical control $[6,7]$. Valid tools that can be used to assess symptom control include simple screening tools (e.g. the 4-item questionnaires endorsed by GINA) [1], categorical symptom control tools (e.g. Royal College of Physicians Three Questions' Tool) [8], and numerical tools (e.g. Asthma Control Questionnaire [ACQ]) [9].

Inhaled corticosteroids (ICS) with or without longacting $\beta_{2}$ agonist (LABA) has been recommended by GINA as the mainstay initial controller treatment, and leukotriene receptor antagonist (LTRA) may be considered as an alternative option or add-on medication at step 2 to 4 [2]. LTRA belongs to anti-leukotrienes and renders anti-inflammatory as well as bronchodilating effects via inhibiting leukotriene receptor or altering leukotriene production. The oral route of administration gives this class of medications an advantage, and they may bring particular benefits for patients with asthma and allergic rhinitis in terms of relieving symptoms and preventing exacerbations [10]. However, the efficacy of LTRA for asthma control remains controversial, with most evidence so far favouring ICS over LTRA as the preferred maintenance therapy for asthma [11]. In China, a survey involving two provinces showed that LTRA was frequently prescribed in combination with ICS/LABA for patients with severe asthma (87.5\% [49/56]) [12].

The INITIAL study (NCT02143739) was a 12-week, multicentre, prospective, observational study of patients with asthma comprising 45 centres across Northern and Southern China [13]. The study aimed to assess asthma severity among newly diagnosed patients as well as their prescribed medications and response to treatment. In the primary analysis of INITIAL data, we observed a high rate of LTRA prescription at baseline (62.1\% [2788/ 4491]), especially in patients with severe asthma (ICS/ LABA plus LTRA, 67.4\% [1654/2455]; LTRA without ICS/LABA, 35.5\% [118/332]) [13]. The current analysis was conducted to further investigate the medications and medication combinations prescribed at baseline during the INITIAL study, with a focus on ICS/LABA and ICS/LABA plus LTRA, and to determine the impact of the change in asthma control criteria between the Global Initiative for Asthma (GINA) 2012 [1] and 2018 guidelines [2].

\section{Methods}

This was a post hoc analysis of a 12-week, multicentre, prospective, observational study performed in patients with asthma from 45 centres across Northern and Southern China between June 2014 and September 2016 (INITIAL, NCT02143739). The protocol, full details of the study population and overall results have previously been reported [13]. Methods specific to this post hoc analysis are briefly described below.

\section{Patients}

Eligible patients were aged $\geq 18$ years, had newly diagnosed asthma without exacerbations within 2 weeks and had not used ICS in the 3 months prior to enrolment. Diagnosis of asthma was made based on lung function test (performed for all patients, airflow limitation, reversibility, and variability based on FEV1 or PEF help confirm the diagnosis), the gold standard for asthma diagnosis, and based on symptoms typical of asthma (i.e. recurrent breathlessness, wheezing, cough, and chest tightness, often triggered by allergens, cold, physical or chemical irritations, viral infection, or exercise; wheezing sound and prolonged respiratory phases during flareups; alleviation of symptoms spontaneously or upon treatment; exclusion of other possible diseases that have similar symptoms), in accord with criteria recommended by Chinese guidelines for the prevention and management of bronchial asthma (2008, [14]). Key exclusion criteria were being diagnosed with COPD and having asthma exacerbations within 2 weeks of study inclusion.

\section{Medications}

Any medications were prescribed as per routine clinical practice at baseline, Week 4, and Week 8 (with no additional monitoring or diagnostic procedures); treatment decisions were not part of the INITIAL study.

\section{Asthma severity and control}

At baseline, patients were screened, and GINA-defined asthma severity [15] and control were assessed [1, 2]. Patient-reported outcomes were assessed using the Asthma Control Questionnaire (5-item version; ACQ-5) [16]. GINA asthma control status and ACQ-5 were assessed at Weeks 4, 8 and 12 . 


\section{Objectives of this post hoc study}

The objectives of the post hoc analysis were to reveal medications prescribed at baseline for asthma, to assess asthma control levels at Week 12 based on GINA 2012 vs GINA 2018 criteria, and to investigate the impact of medications on asthma control.

\section{Statistical analysis}

Descriptive statistics were used in this post hoc analysis. Qualitative variables were described by absolute counts and percentages. No inferential statistics were used.

\section{Results}

\section{Patients}

This post hoc analysis included all 4492 patients in the full analysis set (FAS), and overall, 3587 (74.5\%) completed the study (Table 1) [13].

\section{Initial medications and asthma control at week $\mathbf{1 2}$}

Overall, $90.2 \%$ of patients (4051/4491) were initially prescribed ICS/LABA, with or without other medications. Two thirds of patients $(66.7 \%, 2997 / 4491)$ were initially prescribed ICS/LABA plus one or more additional medications, and $23.5 \%$ of patients $(1054 / 4491)$ were initially prescribed ICS/LABA alone (Table 2). ICS/LABA+LTRA

Table 1 Patient characteristics

\begin{tabular}{|c|c|c|}
\hline & & $\begin{array}{l}N=4492 \\
\mathrm{n}(\%)\end{array}$ \\
\hline \multirow[t]{3}{*}{ Age (years) ${ }^{a}$} & $<30$ & $850(19.0)$ \\
\hline & $30-60$ & 3077 (68.8) \\
\hline & $>60$ & $543(12.2)$ \\
\hline \multirow[t]{2}{*}{$\operatorname{Sex}^{\mathrm{b}}$} & Male & $1819(40.5)$ \\
\hline & Female & $2672(59.5)$ \\
\hline \multirow[t]{3}{*}{ Asthma history ${ }^{b}$} & Yes & $293(6.5)$ \\
\hline & No & $4168(92.8)$ \\
\hline & Unknown & $30(0.7)$ \\
\hline \multirow[t]{3}{*}{ Smoking status ${ }^{b}$} & Never & $3381(75.3)$ \\
\hline & Ever & $635(14.1)$ \\
\hline & Current & 475 (10.6) \\
\hline \multirow[t]{2}{*}{ Area of residence ${ }^{b}$} & Urban & $3208(71.4)$ \\
\hline & Rural & $1283(28.6)$ \\
\hline \multirow[t]{3}{*}{ Allergy history ${ }^{\mathrm{b}}$} & Yes & $992(22.1)$ \\
\hline & No & $2832(63.1)$ \\
\hline & Unknown & $667(14.9)$ \\
\hline \multirow[t]{4}{*}{ GINA 2006 severity $^{a}$} & Intermittent & $173(3.9)$ \\
\hline & Mild & $538(12.0)$ \\
\hline & Moderate & $1013(22.6)$ \\
\hline & Severe & $2767(61.6)$ \\
\hline
\end{tabular}

Table 2 Initial medication categories

\begin{tabular}{ll}
\hline Category, $n$ (\%) & $N=4491$ \\
\hline ICS/LABA & $1054(23.5)$ \\
LTRA & $96(2.1)$ \\
THO & $4(0.1)$ \\
SABA & $15(0.3)$ \\
LAMA/SAMA & $4(0.1)$ \\
ICS & $8(0.2)$ \\
Other single drug & $10(0.2)$ \\
ICS/LABA + other combined drugs ${ }^{\mathrm{a}}$ & $2997(66.7)$ \\
ICS/LABA + LTRA + THO + SABA + others & $49(1.1)$ \\
ICS/LABA + LTRA + THO + others & $374(8.3)$ \\
ICS/LABA + LTRA + SABA + others & $200(4.5)$ \\
ICS/LABA + LTRA + others & $1833(40.8)$ \\
ICS/LABA + THO + others & $159(3.5)$ \\
ICS/LABA + THO + SABA + others & $11(0.2)$ \\
ICS/LABA + SABA + others & $100(2.2)$ \\
ICS/LABA + others & $271(6.0)$ \\
LTRA + Other combined drugs ${ }^{b}$ & $236(5.3)$ \\
THO + other combined drugs ${ }^{c}$ & $16(0)$. \\
Other combined drugs & $30(0.7)$ \\
\hline ICS Inhad cortcosteroid & \\
\hline
\end{tabular}

ICS inhaled corticosteroid, LABA long-acting $\beta_{2}$ agonist, LAMA long-acting muscarinic antagonist, LTRA leukotriene receptor antagonist, SABA short-acting $\beta_{2}$ agonist, SAMA short-acting muscarinic antagonist, THO theophylline alncluding ICS combined with LABA; ${ }^{b}$ Excluding ICS/LABA, ICS or LABA; 'Excluding ICS/LABA, ICS, LABA or LTRA

plus other medication(s) was the most commonly prescribed combination $(40.8 \%, 1833 / 2449$, Table 2).

In patients prescribed ICS/LABA+LTRA versus those prescribed ICS/LABA, the proportions of patients achieving asthma control at Week 12 according to GINA 2012 criteria were $78.1 \%$ vs $80.0,86.5 \%$ vs $85.8,78.5 \%$ vs 71.3 , and $59.6 \%$ vs $61.8 \%$ among those with intermittent, mild, moderate, and severe asthma at baseline, respectively. Across all severity levels, there were no numeric differences in the proportions of patients with any GINA 2012 control levels at Week 12 between those that had been prescribed ICS/LABA and those prescribed ICS/ LABA+LTRA at baseline (Table 3).

Similar results were obtained when control levels were assessed using GINA 2018 criteria. In patients using ICS/LABA+LTRA compared with those using ICS/ LABA, the proportions of patients achieving asthma control at Week 12 were $86.8 \%$ vs $95.9,86.1 \%$ vs 93.2 , $82.1 \%$ vs 85.3 , and $71.9 \%$ vs $77.6 \%$ among those with intermittent, mild, moderate, and severe asthma at baseline, respectively. For both drug combinations, when compared with GINA 2012 criteria, GINA 2018 criteria placed a slightly greater proportion of patients from most severity categories into the controlled asthma category, with a reciprocal decrease in the proportion of 
Table 3 GINA 2012- and 2018-defined control level at Week 12 in patients using ICS/LABA with and without LTRA

\begin{tabular}{|c|c|c|c|c|c|c|c|}
\hline \multirow{2}{*}{$\begin{array}{l}\text { Baseline } \\
\text { asthma } \\
\text { severity }\end{array}$} & \multirow{2}{*}{$\begin{array}{l}\text { Control status } \\
\text { at Week } 12\end{array}$} & \multicolumn{3}{|l|}{ GINA 2012} & \multicolumn{3}{|l|}{ GINA 2018} \\
\hline & & ICS/LABA + LTRA, n (\%) & ICS/LABA, n (\%) & Total, n (\%) & ICS/LABA + LTRA, n (\%) & ICS/LABA, n (\%) & Total, n (\%) \\
\hline \multirow[t]{4}{*}{ Intermittent } & Controlled & $32(78.1)$ & $32(80.0)$ & $64(79.0)$ & $46(86.8)$ & 47 (95.9) & $93(91.2)$ \\
\hline & Partly controlled & $9(22.0)$ & $8(20.0)$ & $17(21.0)$ & $7(13.2)$ & $2(4.1)$ & $9(8.8)$ \\
\hline & Uncontrolled & $0(0)$ & $0(0)$ & $0(0)$ & $0(0)$ & $0(0)$ & $0(0)$ \\
\hline & Total & 41 & 40 & 81 & 53 & 49 & 102 \\
\hline \multirow[t]{4}{*}{ Mild } & Controlled & $122(86.5)$ & $121(85.8)$ & $243(86.2)$ & $167(86.1)$ & $178(93.2)$ & $345(89.6)$ \\
\hline & Partly controlled & $18(12.8)$ & $19(13.5)$ & $37(13.1)$ & $24(12.4)$ & $11(5.8)$ & $35(9.1)$ \\
\hline & Uncontrolled & $1(0.7)$ & $1(0.7)$ & $2(0.7)$ & $3(1.6)$ & $2(1.1)$ & $5(1.3)$ \\
\hline & Total & 141 & 141 & 282 & 194 & 191 & 385 \\
\hline \multirow[t]{4}{*}{ Moderate } & Controlled & $215(78.5)$ & $149(71.3)$ & $364(75.4)$ & $325(82.1)$ & $255(85.3)$ & $580(83.5)$ \\
\hline & Partly controlled & $54(19.7)$ & $58(27.8)$ & $112(23.2)$ & $61(15.4)$ & $43(14.4)$ & $104(15.0)$ \\
\hline & Uncontrolled & $5(1.8)$ & $2(1.0)$ & $7(1.5)$ & $10(2.5)$ & $1(0.3)$ & $11(1.6)$ \\
\hline & Total & 274 & 209 & 483 & 396 & 299 & 695 \\
\hline \multirow[t]{4}{*}{ Severe } & Controlled & $558(59.6)$ & $338(61.8)$ & $896(60.4)$ & 921 (71.9) & $581(77.6)$ & $1502(74.0)$ \\
\hline & Partly controlled & $339(36.2)$ & $185(33.8)$ & $524(35.3)$ & $312(24.4)$ & $150(20.0)$ & $462(22.8)$ \\
\hline & Uncontrolled & $40(4.3)$ & $24(4.4)$ & $64(4.3)$ & $48(3.8)$ & $18(2.4)$ & $66(3.3)$ \\
\hline & Total & 937 & 547 & 1484 & 1281 & 749 & 2030 \\
\hline
\end{tabular}

GINA Global Initiative for Asthma, ICS inhaled corticosteroid, LABA long-acting $\beta_{2}$ agonist, LTRA leukotriene receptor antagonist

patients placed in the partly controlled asthma category (Table 3).

\section{GINA 2012 vs GINA 2018 vs ACQ-5}

Across the entire population, assessment of asthma control as per GINA 2012 criteria indicated a greater proportion of patients having uncontrolled asthma and a lower proportion having controlled asthma than evaluation as per GINA 2018 criteria at every time point (Fig. 1). Assessment according to patients' ACQ-5 scores led to a greater percentage of uncontrolled (ACQ-5 > $1.5)$ and controlled (ACQ-5 $<0.75)$ asthma than classification as per either GINA 2012 or GINA 2018 criteria at all time points (Fig. 1).

When baseline severity was taken into account, asthma control rates were similar for intermittent and mild asthma patients using both classifications (Fig. 2). For patients with moderate and severe asthma, the difference between the two classification systems was more pronounced: assessment as per GINA 2012 criteria indicated a greater percentage of patients having uncontrolled asthma and a lower percentage having controlled asthma than that as per GINA 2018 criteria at every time point (Fig. 2). Irrespective of the GINA criteria used, the proportion of patients with uncontrolled and partly controlled asthma was greater in those with moderate and severe asthma than in patients with intermittent and mild persistent asthma. Furthermore, the distribution of patients between control levels was similar for both GINA 2012 and GINA 2018 criteria.

\section{Discussion}

Both GINA 2012 criteria, in use at the time of the INITIAL study, and the GINA guidelines in place at the time of this analysis (2018) recommend low and medium-/high-dose ICS/LABA as the preferred option for patients at Step 3 and Step 4 [1, 2]. The addition of a third controller (LTRA or theophylline) is an option for patients who are not adequately controlled with a medium-dose ICS/LABA after a trial of 2-3 months for patients at Step 4 [1, 2]. Among ICS/LABA medications, budesonide/formoterol is recommended by GINA 2019 as the preferred formulation of ICS-formoterol at step 1 and 2 based on the evidence of efficacy, and it was also the predominant form used in our population at baseline $(88.9 \%, 3602 / 4051)$ [13], probably because of their availability in one inhaler (e.g. Symbicort) and easy inhaler techniques. Despite these recommendations, ICS/LABA+LTRA (plus others) was the most commonly prescribed initial therapy in $40.8 \%(1833 / 4491)$ of patients, and only 23.5\% (1054/4491) of patients were prescribed ICS/LABA only at baseline. Furthermore, there was no numeric difference in the number of patients achieving asthma control at Week 12, irrespective of whether they had been prescribed ICS/ LABA and ICS/LABA+LTRA at baseline and regardless of their initial severity level. This suggests that LTRA may have been prescribed unnecessarily in some patients in the INITIAL study. The number of medications prescribed and the cost and complexity of a treatment regimen may also have a negative 


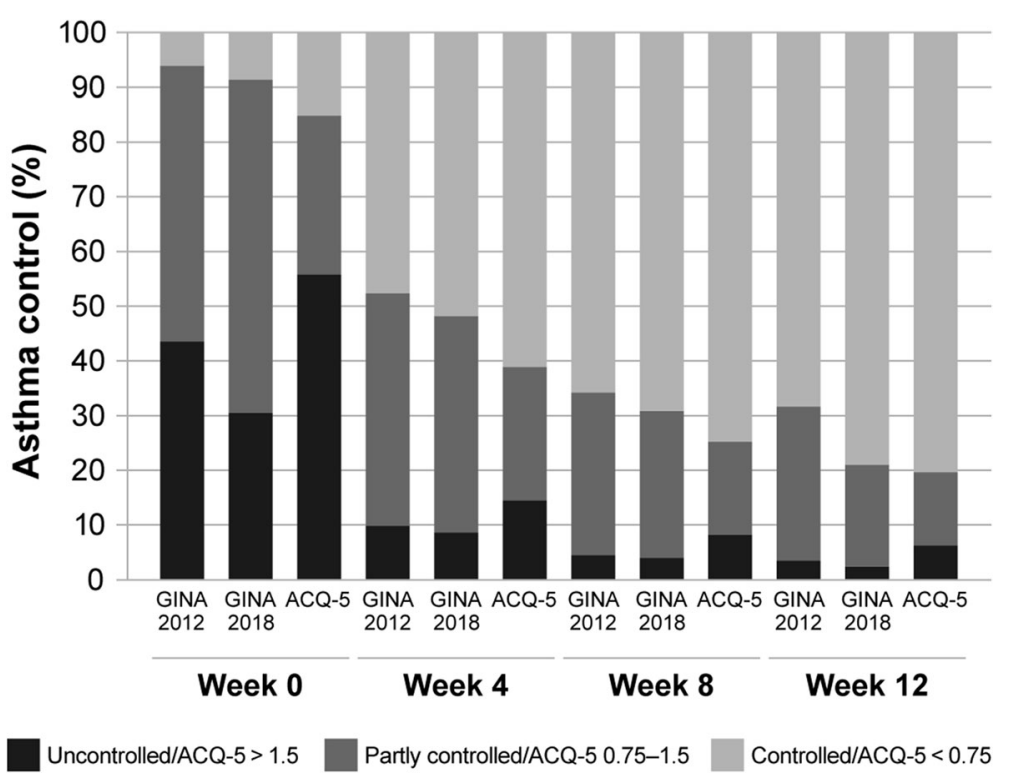

Fig. 1 Asthma control defined by GINA 2012, GINA 2018 and ACQ-5

impact on adherence [2, 17]. As medication costs form the largest component of direct medical expenditures in asthma [18], additional medications place further economic burden on patients and healthcare systems. Studies have shown that patients who adhere to their treatment regimen have better control of their asthma [19].

Despite the lack of clinical benefits with LTRA observed among asthmatic patients in general, it may be a preferred choice for the subset of asthma patients with concomitant allergic rhinitis. Leukotriene plays a critical role in nasal vascular permeability, mucus production, and hypersecretion upon allergen provocation in allergic rhinitis $[20,21]$. By inhibiting the pathogenic process, LTRA is a promising class of medication that can relieve symptoms of rhinitis. Improvement of rhinitis symptoms by LTRA has been demonstrated by a multicentre, placebo-controlled study in patients with symptomatic allergic rhinitis and active asthma (difference between montelukast and placebo in mean change in Daily Rhinitis Symptoms score from baseline, - 0.12 [95\% CI, 0.18 to $-0.06 ; p<$ or $=0.001]$ ) [10]. The efficacy and benefits of LTRA in allergic rhinitis was also supported by results of a meta-analysis study, in which LTRA reduced mean daily rhinitis symptom scores (by 5\% [95\% CI, 3-7\%]) and improved rhinoconjunctivitis quality of life (by 0.3 [95\% CI, 0.24-0.36]) [22]. LTRA (HDM SLIT in particular) has been recommended by GINA 2019 as an add-on medication for patients with allergic rhinitis and $\mathrm{FEV}_{1}>70 \%$ at step 3 and 4 [23]. However, in the INITIAL study, patients with an allergic history only comprised $22.1 \%$ of the patient population [13]. Although these patients might derive benefits from LTRA, the majority of asthmatic patients without allergic rhinitis (77.9\%) still required more effective medications, such as ICS plus LABA, for symptom control and exacerbation prevention [2].

Collection of lung function data was at the discretion of the investigator because lung function testing is not a mandatory requirement of the Chinese Thoracic Society Guidelines 2008 [14]. Therefore, lung function data were not collected for 2942, 2947 and 964 patients at Weeks 4, 8 and 12, respectively, and so GINA 2012 control level could not be determined in these patients. As a result, patient numbers for the comparison of ICS/LABA+LTRA versus ICS/LABA at Week 12 were low, representing only one third (1484) of the FAS. In 2014, GINA criteria underwent a major revision that changed the determination of symptom control by removing lung function testing from the assessment criteria [3]; these criteria have remained unchanged in subsequent reports including the 2018 version [2]. Lung function is now considered, along with exacerbations, as a risk factor for poor asthma outcome [3].

Juniper et al. originally developed the ACQ as a sevenitem measure that included forced expiratory volume in $1 \mathrm{~s}\left(\mathrm{FEV}_{1}\right)$ [9]. In their 2006 paper, they suggest that while the cut-off point between 'well-controlled' and 'not well-controlled' asthma is close to 1.00 , to be confident that patients are categorised correctly in clinical practice, the optimal cut-offs for well-controlled asthma and inadequately controlled asthma should be 0.75 and 1.50, respectively [24]. GINA 2006-defined asthma control (that includes lung function) has been shown to have 


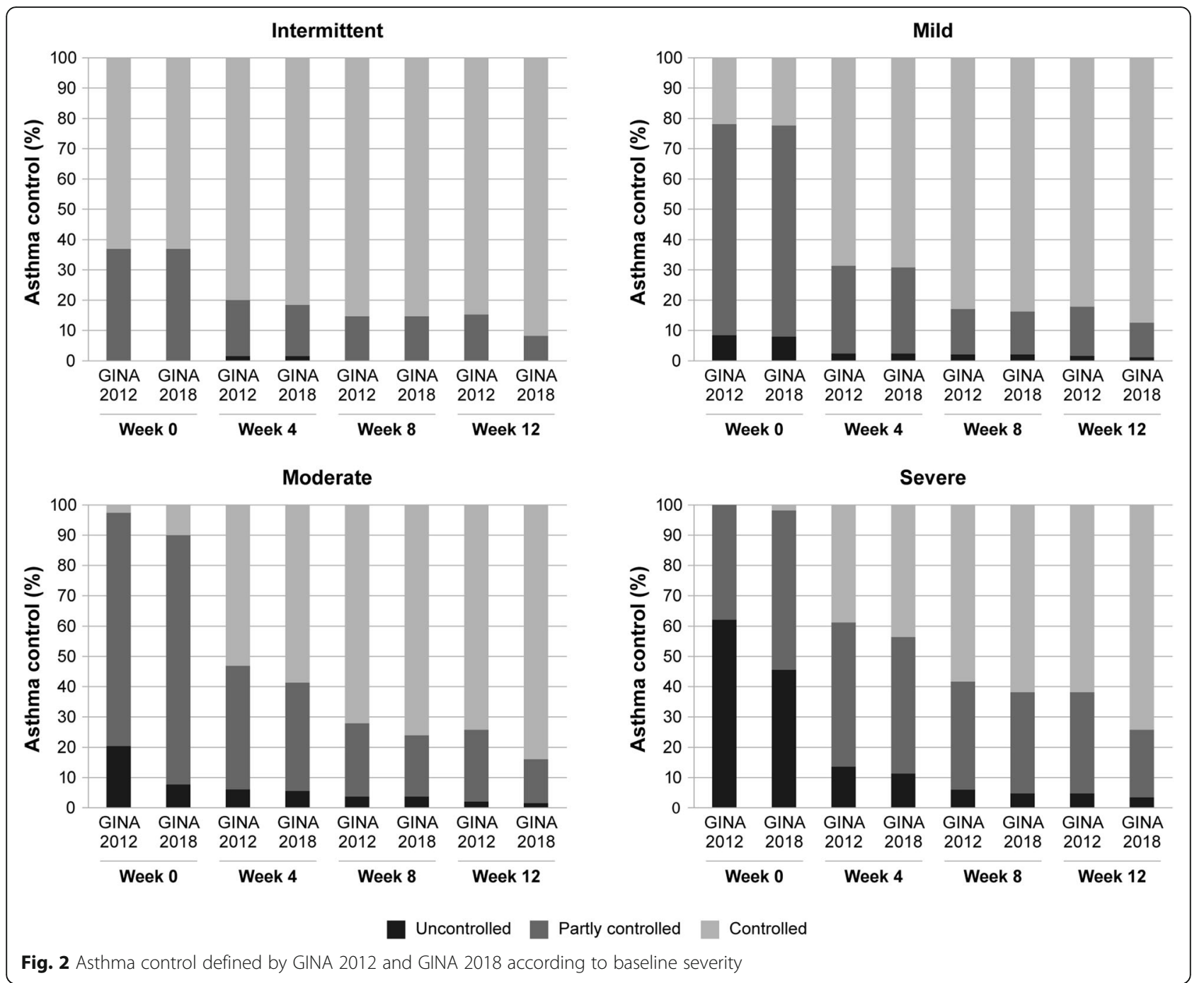

reasonable agreement with the ACQ-5 (that does not include lung function) cut-off points [25]. GINA 2006 controlled, partly controlled and uncontrolled patients had mean ACQ-5 scores of 0.43, 0.75 and 1.62, respectively [25]. Another study of the ACQ by Sastre et al. suggested that the cut-off differs depending on whether lung function is included (ACQ without lung function, equivalent to ACQ-5: 0.83) and depending on which test is used (ACQ with $\mathrm{FEV}_{1}$, equivalent to ACQ-7: 1.14; ACQ with peak expiratory flow [PEF]: 1.28) [26]. However, a more recent study suggested that the cut-off for uncontrolled asthma was 1.00 , despite suggesting a similar cut-off for controlled asthma of 0.50 for both the ACQ-5 (that does not include lung function) and the ACQ-7 (that includes lung function) [27]. In keeping with these findings, the results of the present post hoc analysis suggest that, in this data set, the removal of lung function test results from the GINA 2014 and later criteria reduces the number of patients considered to have uncontrolled asthma and increases the number considered to have controlled asthma. When baseline severity was taken into account, this difference appeared to be driven by patients with moderate and severe asthma. However, control levels did not differ a great deal between the two classifications, supporting the view that lung function does not correlate strongly with asthma symptoms $[28,29]$.

\section{Conclusions}

Over $40 \%$ of patients in the INITIAL study were prescribed ICS/LABA+LTRA; however, in the patients available for analysis at Week 12, this did not alter the levels of GINA 2012- or 2018-defined asthma control compared with ICS/LABA combination alone. While stepping up treatment to include additional controllers is a valid approach after a preliminary trial with a new 
regimen, the addition of LTRA to ICS/LABA as the initial treatment may have been unnecessary in some of these newly diagnosed patients. Physicians should follow GINA and other guidelines by initiating treatment for patients at Step 3 and Step 4 with ICS/LABA for maintenance and relief and then wait 2-3 months before considering stepping up treatment and/or adding additional controllers.

\section{Abbreviations}

ACQ-5: Asthma Control Questionnaire (5-item version); FAS: Full analysis set; FEV 1 : Forced expiratory volume in $1 \mathrm{~s}$; GINA: Global Initiative for Asthma; ICS: Inhaled corticosteroids; ICS/LABA: Inhaled corticosteroid/long-acting $\beta_{2}$ agonist; LTRA: Leukotriene receptor antagonist; PEF: Peak expiratory flow

\section{Acknowledgements}

The authors would like to thank Dr. Tom Priddle of Nucleus Global for medical writing support, which was provided in accordance with Good Publication Practice (GPP3) guidelines (http://www.ismpp.org/gpp3).

\section{Authors' contributions}

$J L, X F, P J, W S, X H, Z J, C L, Z H, X Z$ and $H T$ provided input into the concept and design of the study. JL, XF, PJ, WS, XH, ZJ, CL, ZH, XZ and HT helped draft each stage of the manuscript. All authors have read and approved the final version at the time of submission.

\section{Funding}

This study was funded by AstraZeneca, China.

\section{Availability of data and materials}

The datasets used and/or analysed during the current study are available from the corresponding author on reasonable request.

\section{Ethics approval and consent to participate}

Written consent was obtained from all patients. The study was conducted in accordance with the principles of the Declaration of Helsinki and Good Clinical Practice guidelines. Ethical approval was obtained from the ethics committee of the China-Japan Friendship Hospital, Beijing, China, the principal site, and from the local ethics committee at each site.

\section{Consent for publication}

Not applicable.

\section{Competing interests}

The authors declare that they have no competing interests.

\footnotetext{
Author details

'Department of Pulmonary and Critical Care Medicine, China-Japan Friendship Hospital, No.2 Yinghua East Street, Chaoyang District, Beijing 100029, China. ${ }^{2}$ Department of Pulmonary and Critical Care Medicine, The Affiliated Hospital of Inner Mongolia Medical University, Hohhot 010050, China. ${ }^{3}$ Department of Respiratory Diseases, Tianjin First Center Hospital, Tianjin 300192, China. ${ }^{4}$ Department of Respiratory Diseases, Peking University Shenzhen Hospital, Shenzhen 518035, China. ${ }^{5}$ Department of Respiratory Diseases, First Hospital of Shanxi Medical University, Taiyuan 030001, China. ${ }^{6}$ Department of Respiratory Diseases, The Fifth People's Hospital of Shanghai, Fudan University, Shanghai 200240, China. 'Department of Respiratory Diseases, West China Hospital, Sichuan University, Chengdu 610041, China. ${ }^{8}$ Department of Respiratory Diseases, Suining Central Hospital, Suining 629000, China. ${ }^{9}$ Department of Respiratory Diseases, The First Hospital Affiliated to AMU (Southwest Hospital), Chongqing 400030, China. ${ }^{10}$ Department of Respiratory Diseases, Qingdao Municipal Hospital, Qingdao 266000, China.
}

Received: 22 February 2019 Accepted: 30 January 2020

Published online: 09 April 2020

\section{References}

1. Global Initiative for Asthma (GINA). GINA report: global strategy for asthma management and prevention. 2012. https://ginasthma.org/. Accessed 01 Dec 2017.

2. Global Initiative for Asthma (GINA). GINA report: global strategy for asthma management and prevention. 2018. https://ginasthma.org/. Accessed 01 Nov 2018.

3. Global Initiative for Asthma (GINA). GINA report: global strategy for asthma management and prevention. 2014. https://ginasthma.org/. Accessed 01 Dec 2017.

4. Fuhlbrigge AL, Kitch BT, Paltiel AD, Kuntz KM, Neumann PJ, Dockery DW, et al. FEV (1) is associated with risk of asthma attacks in a pediatric population. J Allergy Clin Immunol. 2001;107(1):61-7.

5. Osborne ML, Pedula KL, O'Hollaren M, Ettinger KM, Stibolt T, Buist AS, et al. Assessing future need for acute care in adult asthmatics: the profile of asthma risk study: a prospective health maintenance organization-based study. Chest. 2007;132(4):1151-61.

6. Jenkins CR, Thien FC, Wheatley JR, Reddel HK. Traditional and patientcentred outcomes with three classes of asthma medication. Eur Respir J. 2005;26(1):36-44.

7. Pellegrino R, Viegi G, Brusasco V, Crapo RO, Burgos F, Casaburi R, et al. Interpretative strategies for lung function tests. Eur Respir J. 2005;26(5):948-68.

8. Pinnock H, Burton C, Campbell S, Gruffydd-Jones K, Hannon K, Hoskins G, et al. Clinical implications of the Royal College of Physicians three questions in routine asthma care: a real-life validation study. Prim Care Respir J. 2012; 21(3):288-94.

9. Juniper EF, O'Byrne PM, Guyatt GH, Ferrie PJ, King DR. Development and validation of a questionnaire to measure asthma control. Eur Respir J. 1999;14(4):902-7.

10. Philip G, Nayak AS, Berger WE, Leynadier F, Vrijens F, Dass SB, et al. The effect of montelukast on rhinitis symptoms in patients with asthma and seasonal allergic rhinitis. Curr Med Res Opin. 2004;20(10):1549-58.

11. Chauhan BF, Ducharme FM. Anti-leukotriene agents compared to inhaled corticosteroids in the management of recurrent and/or chronic asthma in adults and children. Cochrane Database Syst Rev. 2012;5:CD002314.

12. Wang G, Wang F, Gibson PG, Guo M, Zhang WJ, Gao P, et al. Severe and uncontrolled asthma in China: a cross-sectional survey from the Australasian severe asthma network. J Thorac Dis. 2017;9(5):1333-44.

13. Lin J, Fu X, Jiang P, Song W, Hu X, Jie Z, et al. INITIAL - an observational study of disease severity in newly diagnosed asthma patients and initial response following 12 weeks' treatment. Sci Rep. 2019;9(1):1254.

14. Society CT. Guideline for management of asthma (definition, diagnosis, treatment and management of asthma) from asthma study Group of Chinese Thoracic Society. Zhonghua Jie He He Hu Xi Za Zhi. 2008;31:177-85.

15. Global Initiative for Asthma (GINA). GINA report: global strategy for asthma management and prevention. 2006. https://ginasthma.org/. Accessed 01 Dec 2017.

16. Juniper EF, O'Byrne PM, Roberts JN. Measuring asthma control in group studies: do we need airway calibre and rescue beta2-agonist use? Respir Med. 2001;95(5):319-23.

17. Boulet $L P$, Vervloet $D$, Magar $Y$, Foster JM. Adherence: the goal to control asthma. Clin Chest Med. 2012;33(3):405-17.

18. Bahadori K, Doyle-Waters MM, Marra C, Lynd L, Alasaly K, Swiston J, et al. Economic burden of asthma: a systematic review. BMC Pulm Med. 2009;9:24

19. Baddar S, Jayakrishnan B, Al-Rawas OA. Asthma control: importance of compliance and inhaler technique assessments. J Asthma. 2014:51(4):429-34.

20. Liu YC, Khawaja AM, Rogers DF. Effects of the cysteinyl leukotriene receptor antagonists pranlukast and zafirlukast on tracheal mucus secretion in ovalbumin-sensitized Guinea-pigs in vitro. Br J Pharmacol. 1998;124(3):563-71.

21. Shirasaki H, Asakura K, Narita S, Kataura A. The effect of a cysteinyl leukotriene antagonist, ONO-1078 (pranlukast) on agonist- and antigen-induced nasal microvascular leakage in Guinea pigs. Rhinology. 1998;36(2):62-5.

22. Wilson AM, O'Byrne PM, Parameswaran K. Leukotriene receptor antagonists for allergic rhinitis: a systematic review and meta-analysis. Am J Med. 2004; 116(5):338-44.

23. Global Initiative for Asthma (GINA). GINA report: global strategy for asthma management and prevention. 2019. https://ginasthma.org/. Accessed 30 Oct 2019. 
24. Juniper EF, Bousquet J, Abetz L, Bateman ED, Committee G. Identifying 'well-controlled' and 'not well-controlled' asthma using the asthma control questionnaire. Respir Med. 2006;100(4):616-21.

25. O'Byrne PM, Reddel HK, Eriksson G, Ostlund O, Peterson S, Sears MR, et al. Measuring asthma control: a comparison of three classification systems. Eur Respir J. 2010;36(2):269-76.

26. Sastre J, Olaguibel J, Vega JM, Del Pozo V, Picado C, Lopez VA. Cut-off points for defining asthma control in three versions of the asthma control questionnaire. J Asthma. 2010;47(8):865-70.

27. Olaguibel JM, Quirce S, Julia B, Fernandez C, Fortuna AM, Molina J, et al. Measurement of asthma control according to global initiative for asthma guidelines: a comparison with the asthma control questionnaire. Respir Res. 2012;13:50.

28. Kerstjens HA, Brand PL, de Jong PM, Koeter GH, Postma DS. Influence of treatment on peak expiratory flow and its relation to airway hyperresponsiveness and symptoms. The Dutch CNSLD Study Group. Thorax. 1994:49(11):1109-15.

29. Werner CU, Linde K, Schaffner J, Storr C, Schneider A. Weekly selfmeasurement of FEV1 and PEF and its impact on ACQ (asthma control questionnaire)-scores: 12-week observational study with 76 patients. NP Prim Care Respir Med. 2017;27(1):64

\section{Publisher's Note}

Springer Nature remains neutral with regard to jurisdictional claims in published maps and institutional affiliations.

Ready to submit your research? Choose BMC and benefit from:

- fast, convenient online submission

- thorough peer review by experienced researchers in your field

- rapid publication on acceptance

- support for research data, including large and complex data types

- gold Open Access which fosters wider collaboration and increased citations

- maximum visibility for your research: over $100 \mathrm{M}$ website views per year

At BMC, research is always in progress.

Learn more biomedcentral.com/submissions 